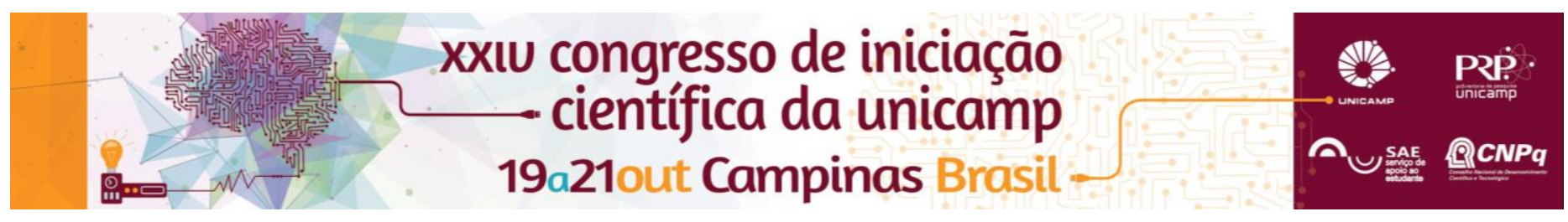

\title{
Avaliação e controle dos instrumentais utilizados em sala operatória no centro cirúrgico de um hospital universitário.
}

\author{
Adrielly Raymundo Gaspar, Vitor Marraschi, Jocimara Bispo Torres, Gabriela Rodrigues Ribeiro, Marlene \\ Nakamura, Ana Paula Boaventura.
}

\section{Resumo}

Esta pesquisa teve como objetivo avaliar quantitativamente os instrumentais cirúrgicos utilizados durante as cirurgias realizadas no Centro Cirúrgico de um hospital universitário. Trata-se de um estudo quantitativo e descritivo, realizado a partir do levantamento de dados com a observação das cirurgias realizadas e dos instrumentais cirúrgicos utilizados. Foram observadas 168 cirurgias, sendo: torácicas 30(11,19\%), abdominais $48(28,57 \%)$, cabeça e pescoço e neurológicas $42(25 \%)$ e outras especialidades $42(25 \%)$ como cirurgias vasculares, plástica, pediátricas, ortopédicas e de urgência. sendo avaliados 16034 instrumentais com um percentual geral de não utilização de $18,73 \%$.Na prática diária, recomenda-se os cuidados, controles e gerenciamento dos instrumentais cirúrgicos no período transoperatório.

Palavras-chave: Controle de Custos, Instrumentais Cirúrgicos, Centro cirúrgico.

\section{Introdução}

O gerenciamento dos materiais dentro de uma sala operatória é tarefa do enfermeiro que atua no CC e é parte fundamental da assistência de enfermagem perioperatória que envolve os cuidados e a segurança do paciente nos períodos pré, trans e pós-operatorio. Todo o processo de cuidar em uma sala cirúrgica para que a cirurgia aconteça depende diretamente da assistência de enfermagem transoperatória. ${ }^{1-2}$

Este trabalho apresentou o objetivo de avaliar o número de instrumentos cirúrgicos utilizados e não utilizados, que compõem as caixas cirúrgicas das cirurgias realizadas no hospital universitário no $1^{\circ}$ semestre de 2016.

\section{Resultados e Discussão}

A coleta de dados foi realizada através da observação, ao final da cirurgia, dos instrumentais que não eram colocados na mesa cirúrgica, ou seja, que permaneceram na caixa vinda da CME durante todo o procedimento.

No cálculo amostral foi considerada uma proporção $p$ igual a 0,50 , a população considerada para 0 cálculo do tamanho amostral era composta de 1566 cirurgias de cirurgias realizadas no primeiro semestre de 2015. Além disso, foi assumido um erro amostral de 5\% e um nível de significância de $5 \%$. Com isso, o tamanho amostral calculado foi de 162 cirurgias.

Tabela 1 - Distribuição do total de instrumentais nas caixas das cirurgias torácicas. Campinas, 2016. $(n=162)$

\begin{tabular}{l|r}
\hline \multicolumn{2}{c}{ Cirurgias Totais } \\
\hline Média de caixas utilizadas por cirurgias & 3 \\
\hline Total de instrumentais no início da cirurgia & 16034 \\
\hline Média de instrumentais no início da cirurgia & 99,88 \\
\hline Total de instrumentais NÃO utilizados & 3003 \\
\hline Média de instrumentais NÃO utilizados & 18,82 \\
\hline Percentual final de instrumentais NÃO utilizados & 18,73 \\
\hline
\end{tabular}

Verifica-se que os instrumentais de síntese apresentaram maior percentual de não utilização nesta amostra.
Tabela 2 - Distribuição dos instrumentais por tempos cirúrgicos de cirurgias torácicas. Campinas, 2016. $(\mathrm{n}=162)$

\begin{tabular}{c|lr}
\hline \multicolumn{3}{c}{ Tempos cirúrgicos de todas as cirurgias } \\
\hline \multirow{4}{*}{ Diérese } & Instrumentais no início da cirurgia & 1538 \\
\cline { 2 - 3 } & Instrumentais NÃO Utilizados & 270 \\
\hline \multirow{4}{*}{ Hemostasia } & Instrumentais no início da cirurgia & $\mathbf{1 7 , 5 6 \%}$ \\
\cline { 2 - 3 } & Instrumentais NÃO Utilizados & 5608 \\
\hline \multirow{4}{*}{ Súntese } & Instrumentais no início da cirurgia & 1058 \\
\cline { 2 - 3 } & Instrumentais NÃO Utilizados & $\mathbf{1 8 , 8 7 \%}$ \\
\cline { 2 - 3 } & Instrumentais no início da cirurgia & 3156 \\
\cline { 2 - 3 } & Instrumentais NÃO Utilizados & $\mathbf{1 4 7}$ \\
& & $\mathbf{1 4 2 \%}$ \\
\hline \multirow{3}{*}{ Outros } & Instrumentais no início da cirurgia & $\mathbf{2 3 , 2 8 \%}$ \\
\cline { 2 - 3 } & Instrumentais NÃO Utilizados & 4624 \\
\hline
\end{tabular}

\section{Conclusões}

$\mathrm{Na}$ prática diária, os cuidados, controles e gerenciamento dos instrumentais cirúrgicos no período transoperatório é de responsabilidade do enfermeiro que atua no CC e é parte fundamental para a assistência de enfermagem garantindo a qualidade e segurança do paciente, porém percebe-se que muito dos instrumentais que compõem as caixas cirúrgicas não são usados e passam novamente pelo processo de esterilização gerando custos desnecessários.

\section{Agradecimentos}

À Direção de Enfermagem do Centro Cirúrgico e Centro Cirúrgico Ambulatorial do Hospital das Clínicas da Unicamp e a todos que colaboraram na elaboração do projeto.

1.Rothrock JC. Alexander: Cuidados de Enfermagem ao Paciente Cirúrgico, $14^{\mathrm{a}}$. edição, Rio de Janeiro: Elsevier, 2011.1272p

2. Paula JRA, Silva RCR, Vedovato CA, Boaventura AP.Instrumentais nas caixas cirúrgicas: avaliação de custo. 20(2): 73-79, 2015. 